\title{
Article \\ A Titania-Supported Polyoxometalate and Au Cocatalyst for Efficient Photocatalytic Environmental Remediation
}

\author{
Feng Lin ${ }^{1,2,+} \mathbb{D}$, Yun Yang ${ }^{3,+}$, Zhen Zhang ${ }^{1}$, Nanfang Tang ${ }^{2, *}$ and Guangqi Zhu ${ }^{2, *}$ \\ 1 Key Laboratory of New Energy and Rare Earth Resource Utilization of State Ethnic Affairs Commission, Key \\ Laboratory of Photosensitive Materials and Devices of Liaoning Province, School of Physics and Materials \\ Engineering, Dalian Minzu University, 18 Liaohe West Road, Dalian 116600, China; \\ linfeng@dlnu.edu.cn or flin@dicp.ac.cn (F.L.); zhangzhenwz@outlook.com (Z.Z.) \\ 2 Dalian Institute of Chemical Physics, Chinese Academy of Sciences, 457 Zhongshan Road, \\ Dalian 116023, China \\ 3 Hohhot Enforcement Branch of Ecological Environment Comprehensive Administrative Law, \\ Hohhot 010000, China; nmlucky@163.com \\ * Correspondence: nftang@dicp.ac.cn (N.T.); zhugq@dicp.ac.cn (G.Z.) \\ + Both authors contributed equally to this work.
}

Citation: Lin, F.; Yang, Y.; Zhang, Z.; Tang, N.; Zhu, G. A Titania-

Supported Polyoxometalate and $\mathrm{Au}$ Cocatalyst for Efficient Photocatalytic Environmental Remediation. Catalysts 2021, 11, 1045. https:// doi.org/10.3390/catal11091045

Academic Editors: Edward G. Gillan and María Victoria López Ramón

Received: 26 July 2021

Accepted: 26 August 2021

Published: 28 August 2021

Publisher's Note: MDPI stays neutral with regard to jurisdictional claims in published maps and institutional affiliations.

Copyright: (c) 2021 by the authors. Licensee MDPI, Basel, Switzerland. This article is an open access article distributed under the terms and conditions of the Creative Commons Attribution (CC BY) license (https:// creativecommons.org/licenses/by/ $4.0 /)$.

\begin{abstract}
Photocatalysis has been considered an effective method for environmental purification and pollutant removal, with many experiments having being performed. The sustainable development of environmentally friendly materials that can photocatalytically oxidize and degrade contaminants is widely studied. Here, we report the results of the photocatalytic oxidation of contaminants (over 99\% conversion of the contaminants was achieved) on a tri-component photocatalyst by the simultaneous decoration of $\mathrm{Au}$ nanoparticles and a new type of Sn-substituted Keggin structure polyoxometalate (POM) on a $\mathrm{TiO}_{2}$ semiconductor (denoted as AuPT). The light absorption and the electron-hole pair separation capacity of $\mathrm{TiO}_{2}$ was significantly ameliorated on AuPT. The synergistic effect of the $\mathrm{Au}$ resonance energy transfer (RET) course and the POM redox transformation can be advantageous to the efficient transmission of photogenerated electrons and holes in a way that achieves efficient photocatalytic oxidation of contaminants.
\end{abstract}

Keywords: $\mathrm{Au}$; polyoxometalate; photocatalytic oxidation; $\mathrm{TiO}_{2}$; contaminant

\section{Introduction}

$\mathrm{TiO}_{2}$ photocatalysts feature a strong oxidation ability, high physicochemical stability, and rich properties and are non-toxic. Hence, they have great application potential in the degradation of pollutants in environmental water and air $[1,2]$. Water purification methods at present include, for example, ozonation and chlorination, which employ strong oxidants that cause some problems to the environment. Environmentally friendly materials that can photocatalytically oxidize and degrade pollutants purify polluted water with a low energy consumption and are attracting increasing attention [3]. Nevertheless, only UV light can be absorbed by $\mathrm{TiO}_{2}$, which occupies ca. $3 \%$ of the solar spectrum. For the effective use of sunlight, it is necessary to explore visible-light-responsive photocatalysts. Recent research has reported that surface modification/composite materials could expand the light absorption of semiconductors towards longer wavelengths [4-7], which could enhance the utilization efficiency of the incident light. Consequently, the photocatalytic activity of photocatalysts can be greatly improved.

Polyoxometalate (POM), which often acts as an acid catalyst due to its acidity, can also be employed for catalyzing alcohol compounds due to its proven redox property [8,9]. Some new POMs with a Keggin structure have been studied, such as the $\left[\mathrm{XM}_{12} \mathrm{O}_{40}\right]^{\mathrm{n}-}$ structure ( $\mathrm{X}=\mathrm{Co}, \mathrm{Ge}, \mathrm{P}, \mathrm{Si}, \mathrm{As}, \mathrm{Zn}, \mathrm{Ga} ; \mathrm{M}=$ metal/organo-metallic) [10-12]. A metalsubstituted derivative of the POM has numerous features such as adjustable redox voltage, a highly stable redox state, and multi-electron transfer and is broadly employed in the 
sector of catalysis and other reactions [12]. The introduction of the inorganic element $\mathrm{Sn}$ to form a new polyoxometalate Keggin structure has rarely been reported. Additionally, tin has been shown to promote oxidation reactions on catalysts [11,12]. In short, POM could make a significant difference in catalytic reactions because of its concurrent quality of acidity and redox state.

On the other hand, gold-based catalytic systems have exhibited strong activity and selectivity in several organic reactions, e.g., the catalytic oxidation of carbon oxide [13,14] and propene epoxidation $[15,16]$. The surface plasmon resonance (SPR) effect of Au nanoparticles (NPs) also offers an opportunity for exciting $\mathrm{e}^{-}-\mathrm{h}^{+}$pairs in a semiconductor through the shift of plasmonic energy from the metal to the semiconductor [17-19]. Thus far, there are several mechanisms of SPR-induced charge separation, such as direct electron transfer (DET), resonance energy transfer (RET), and the SPR-mediated local electromagnetic field (LEMF) course [18-20]. DET relies on the arrangement between the band levels of the semiconductor and the Fermi level of the plasmonic metal. The LEMF/RET process results in charge separation and carrier creation in semiconductors, which are advantageous for improving photocatalytic activity [4,18-20].

In this paper, we prepared an SPR-mediated photocatalyst with visible-light response by the decoration of $\mathrm{Au}$ NPs on a composite of a $\mathrm{TiO}_{2}$ semiconductor and a new type of POM (Sn-substituted Keggin structure) (denoted as AuPT). Under visible-light irradiation $(\lambda \geq 420 \mathrm{~nm})$, the photocatalytic oxidation of phenol, dyes, mercaptan, thiophene, and other organic pollutants features high photocatalytic activity (the conversion rate of pollutants is more than $99 \%$ ). The outcomes show that the synergistic effect of the Au SPR effect and the redox transformation of POM are conducive to the photocatalytic oxidation of contaminants.

\section{Results and Discussion}

\subsection{Characterization of Photocatalysts}

Figure 1a exhibits the XRD patterns of the synthesized POM, 0.25 AuPT, and standard cards for anatase and rutile. The XRD pattern of the POM shows that the POM possesses an amorphous structure, and no sharp diffraction peaks appear in the XRD pattern of the POM. For $0.25 \mathrm{AuPT}$, the diffraction peaks result from anatase and rutile, and the typical phase structure of $\mathrm{TiO}_{2}$ (P25) is well preserved. The amorphous structure of POM does not affect the typical crystal structure of $\mathrm{TiO}_{2}$ in the composite process of catalyst preparation.
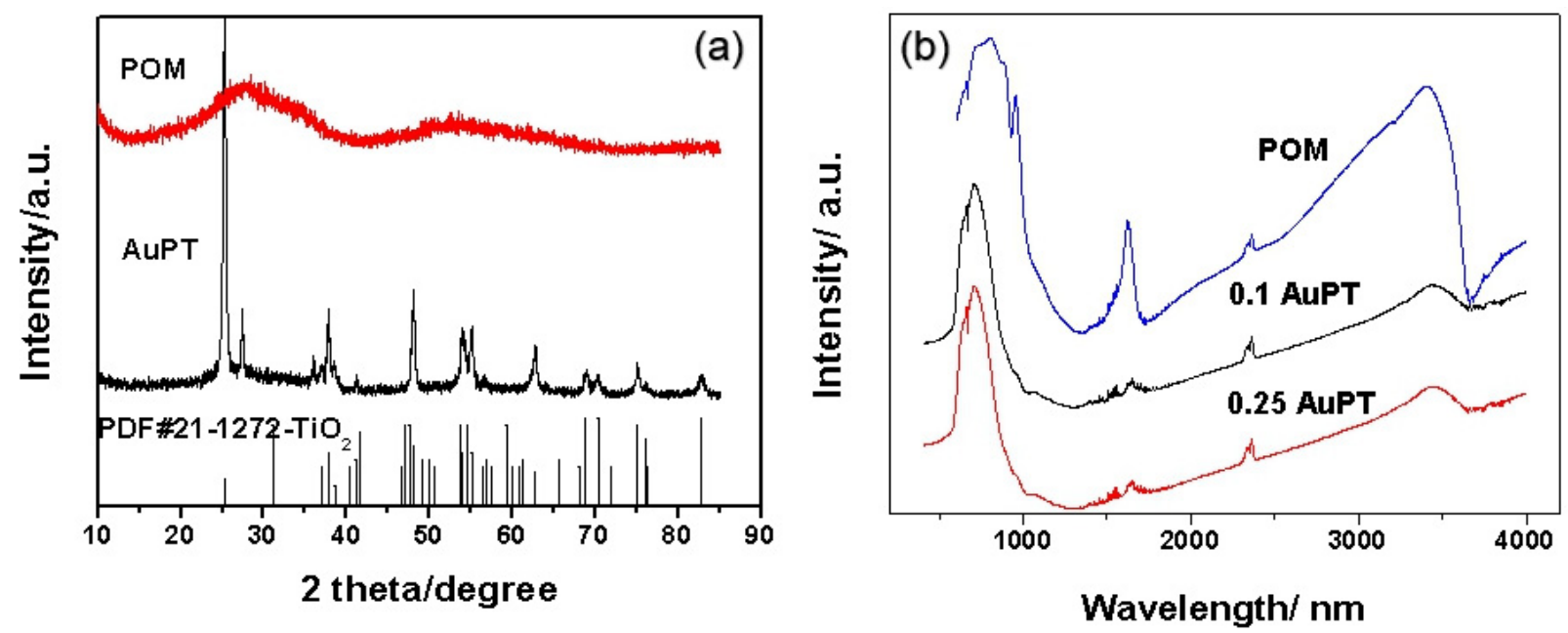

Figure 1. (a) The XRD patterns and (b) infrared spectra of the i AuPT and POM catalysts, and the standard cards for anatase (No. 21-1272) and rutile (No. 21-1276).

The IR spectra of a new POM featuring a Keggin structure (Figure 1b) show the fingerprints $\left(1200-400 \mathrm{~cm}^{-1}\right)$ of the POM. The three obvious bands at 943,873 , and $760 \mathrm{~cm}^{-1}$ 
resulted from antisymmetric and stretching vibrations of $\mathrm{W}=\mathrm{Od}, \mathrm{W}-\mathrm{Ob}-\mathrm{W}$, and $\mathrm{W}-\mathrm{Oc}-\mathrm{W}$, respectively [21-23]. The band at $442 \mathrm{~cm}^{-1}$ originated from the bending vibration of $\mathrm{O}-\mathrm{C}_{\mathrm{O}}-\mathrm{O}$ [23]. These infrared outcomes proved that the new POM Co $\mathrm{CI}_{11} \mathrm{~W}_{11} \mathrm{O}_{39} \mathrm{Sn}_{\mathrm{IV}} \mathrm{OH}_{8}$ was successfully synthesized. In the structure of the POM, the Co was at the center of the tetrahedron, while the Sn was located in the octahedron [21-23]. The novel POM was composed of several transition metal ions featuring high proton conductivity. Thus, good ion conductivity of POM can improve the conductivity of the electrode and accelerate the electron transfer process [24,25]. After being assembled into $\mathrm{TiO}_{2}$, there was no obvious change in the IR spectra. Thus, we can speculate that the Keggin structure of the POM was well-preserved.

Figure 2 exhibits the SEM images and elemental maps of $\mathrm{Au}, \mathrm{Ti}$, and $\mathrm{W}$ of the 0.25 AuPT catalyst. We found that the POM was dispersed onto the surface of $\mathrm{TiO}_{2}$ (Figure 2a,b), and the $\mathrm{TiO}_{2}$ NPs featured diameters of approximately 20-50 nm (Figure 2d). The Au NPs (Figure 2c-e, marked in red circles) were highly dispersed on the surface of $\mathrm{TiO}_{2}$ and POM, and the typical size of the Au was estimated to be ca. 2-5 nm. The HR-TEM and EDX images further revealed that $\mathrm{Au}$ was homogeneously distributed on $\mathrm{TiO}_{2}$ and POM (Figure 2e), though only a few Au single atoms were observed. The Au loading was determined to be $1.1 \mathrm{wt}$ \% by EDX analysis (Figure S2: The element composition of AuPT catalyst. Table S1: The element composition and proportion of AuPT catalyst.), and we could clarify the elemental ratio of Co:W:Sn, which is about 1.1:11:1.3 (calculated by Table S1: The element composition and proportion of AuPT catalyst.). For the composite $\mathrm{AuPT}$ catalyst, there were some good contacts in the interface of $\mathrm{Au} / \mathrm{TiO}_{2}$ and $\mathrm{POM} / \mathrm{TiO}_{2}$, which may be favorable for the transfer of electrons and holes.
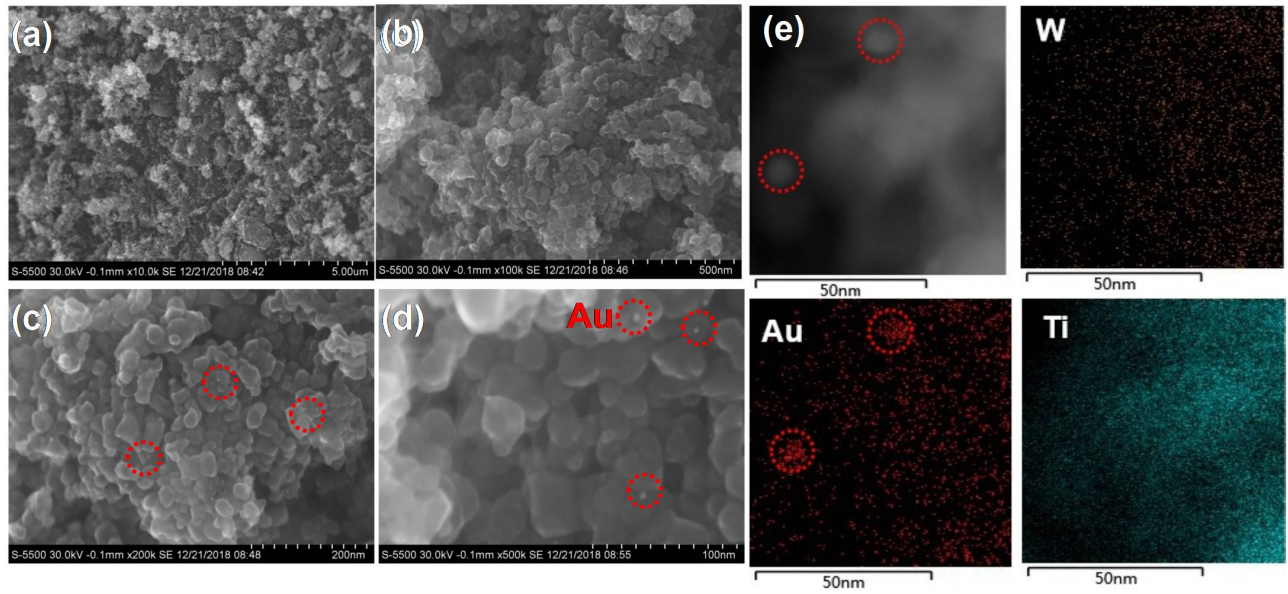

Figure 2. SEM images (a-d) and elemental maps of Au, Ti and W for AuPT catalyst (e) (Au species are in red, Ti species are in blue, and $\mathrm{W}$ species are in orange).

XPS was employed to investigate the combined state of the Co, W, and Sn elements present in the POM material. Figure 3 shows the asymmetrical X-ray photoelectron spectrum of the Co 2P, W 4f, and Sn $3 \mathrm{~d}$ levels of the POM. CoO 2 $\mathrm{p}_{3 / 2}$ and CoO 2 $\mathrm{p}_{1 / 2}$ XPS exhibited small peaks at $781.7 \mathrm{eV}$ and $793.2 \mathrm{eV}$, respectively. $\mathrm{WO}_{3} 4 \mathrm{f}_{7 / 2}$ and $\mathrm{WO}_{3} 4 \mathrm{f}_{5 / 2} \mathrm{XPS}$ of the POM exhibited sharp peaks at $35.65 \mathrm{eV}$ and $37.8 \mathrm{eV}$, respectively. $\mathrm{SnO}_{2} 3 \mathrm{~d}_{5 / 2}$ and $\mathrm{SnO}_{2} 3 \mathrm{~d}_{3 / 2}$ XPS of the POM exhibited sharp peaks at $486.6 \mathrm{eV}$ and $495.1 \mathrm{eV}$, respectively, and the binding energy (BE) showed no alteration. The results indicate that the Co, $\mathrm{W}$, and Sn elements contained in the POM were present in the combined state of $2+, 6+$, and $4+$, respectively. The oxidation state of the metals may have originated from the Keggin structure of the POM, which was well preserved. 

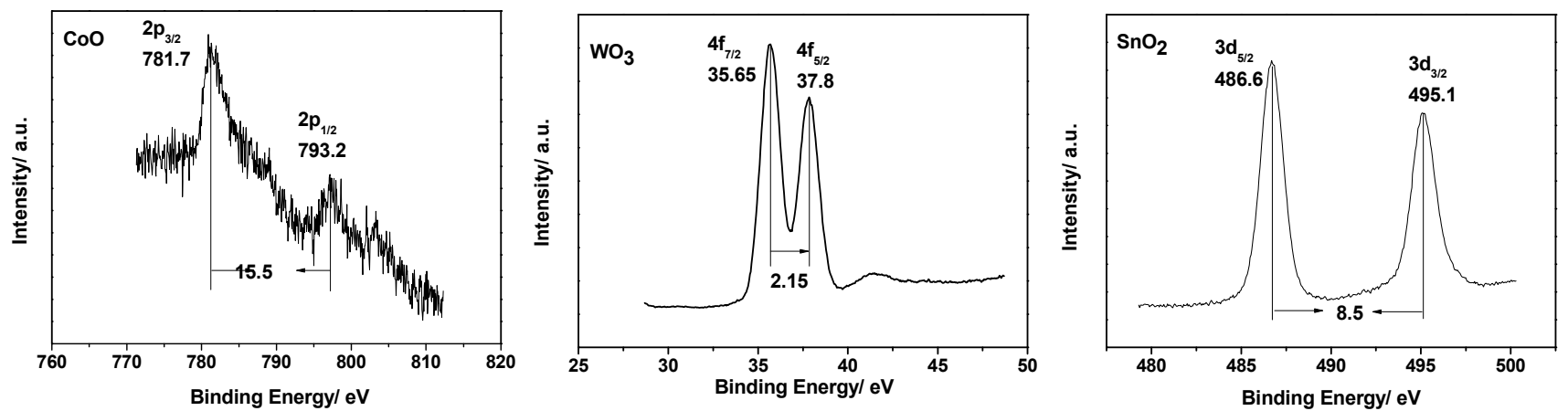

Figure 3. Co 2P, W 4f, and Sn 3d XPS of fresh POM material.

\subsection{Effect of Au SPR on the Catalytic Activities of Photocatalysts}

The UV-vis diffuse reflectance spectra of the POM and AuPT with different gold loadings are shown in Figure 4. As is known, $\mathrm{TiO}_{2}$ is a UV-responsive material. The POM showed strong absorption in the ultraviolet region up to about $275 \mathrm{~nm}$, and weak absorption between $275 \mathrm{~nm}$ to $400 \mathrm{~nm}$. Thus, the $\mathrm{POM}$ and $\mathrm{TiO}_{2}$ are UV-light-responsive materials. When the PT was loaded with the Au NPs, a new absorption band appeared in the AuPT absorption curves with the center at $550 \mathrm{~nm}$. The Au SPR course concentrated the incident photon energy into plasmon oscillations. Then, the concentrated energy contained in the local plasma oscillation was transferred to the semiconductor, resulting in a charge split in the catalyst. In brief, the light absorption of the AuPT catalyst was greatly expanded in the red light direction.

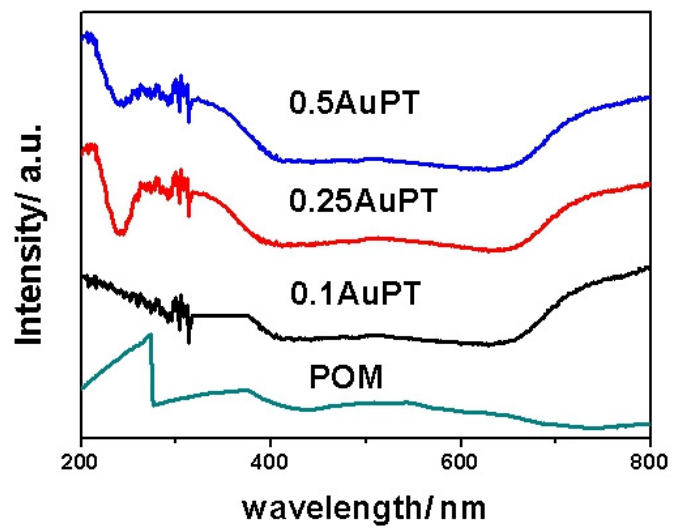

Figure 4. UV-visible diffuse reflectance spectra of POM and AuPT with different Au loadings.

We researched the photocatalytic performance of i Au/2 ST catalysts in terms of the degradation of contaminants (e.g., RhB, thiol, and phenol). Aligning with the light adsorption spectra in Figure 4, neither $\mathrm{POM}$ nor $\mathrm{TiO}_{2}$ could work under the visible light $(\lambda \geq 420 \mathrm{~nm})$. The i AuPT catalysts exhibited better photocatalytic activity in the photocatalytic oxidation reaction than $\mathrm{POM}$ or $\mathrm{TiO}_{2}$. Compared with $\mathrm{TiO}_{2}$, the SPR effect of the $\mathrm{Au}$ NPs improved the activity of the i AuPT catalysts. Figure 5a exhibits the degradation of RhB on the fresh i AuPT catalysts. Among these newly prepared i AuPT catalysts, 0.25 AuPT featured the highest photocatalytic activity. The RhB dye was completely degraded by $0.25 \mathrm{AuPT}$ within $1 \mathrm{~h}(\lambda \geq 420 \mathrm{~nm})$. On the contrary, complete mineralization of the RhB dye on i AuPT $(\mathrm{i}=0.1,0.5,1)$ took over $1.5 \mathrm{~h}$. After the gold loading exceeded $0.25 \mathrm{wt} . \%$, the photocatalytic activities of i AuPT decayed. It is possible that the amount of Au NPs was too large, and more active sites were covered on the ST surface, thereby hindering the combination of reactive molecules/superoxide with the PT surface. For comparison, RhB was only degraded by ca. $60 \%$ on PT and ca. $79 \%$ on $0.25 \mathrm{Au} / \mathrm{TiO}_{2}$ after $2.5 \mathrm{~h}$. Figure $5 \mathrm{~b}$ and c show the degradation of MO and phenol on the i AuPT catalyst. There were similar activity trends on the catalysts with different Au loadings for the degradation of these 
contaminants. Under the same conditions, $\mathrm{MO}$ and phenol were completely degraded in $1.5 \mathrm{~h}$ on $0.25 \mathrm{AuPT}$. MO was only degraded by ca. $55 \%$ on PT and ca. $70 \%$ on $0.25 \mathrm{Au} / \mathrm{TiO}_{2}$ after $2.5 \mathrm{~h}$, and phenol was only degraded by ca. $42 \%$ on $\mathrm{PT}$ and ca. $55 \%$ on $0.25 \mathrm{Au} / \mathrm{TiO}_{2}$ after $3 \mathrm{~h}$. However, on $\mathrm{TiO}_{2}$, the complete degradation of $\mathrm{RhB}, \mathrm{MO}$, and phenol with the visible-light irradiation took more than $2 \mathrm{~h}, 3.5 \mathrm{~h}$, and $7 \mathrm{~h}$, respectively, and on POM, the complete degradation of RhB, MO, and phenol took more than $2.5 \mathrm{~h}, 4 \mathrm{~h}$, and $8 \mathrm{~h}$, respectively. We found that when the Au NPs and POM were co-loaded on $\mathrm{TiO}_{2}$, the degradation rate was markedly enhanced, much higher than that of $\mathrm{PT}, \mathrm{Au} / \mathrm{TiO}_{2}$, and bare $\mathrm{TiO}_{2}$. The great enhancement probably originated from the synergistic effect of the POM and $\mathrm{Au}$ on $\mathrm{TiO}_{2}$. Hence, these outcomes indicate that the photocatalytic degradation of $\mathrm{RhB}, \mathrm{MO}$, and phenol can be markedly enhanced by simultaneously loading Au NPs and POM. The SPR effects of the Au NPs and POM are important for the improvement of the photocatalytic performance of $\mathrm{TiO}_{2}$. We also studied the photocatalytic degradation of RhB on AuPT, $\mathrm{PT}, \mathrm{Au} / \mathrm{TiO}_{2}$, and bare $\mathrm{TiO}_{2}$ for one hour with illumination of different monochromatic light levels, such as $380 \mathrm{~nm}, 420 \mathrm{~nm}$, and $540 \mathrm{~nm}$, to find the wavelength dependence of the catalysts' performance. As Figure S1 shows, although we used monochromatic light with the three wavelengths as a light source, 0.25 AuPT was always the most effective catalyst among these catalysts, which is similar to the performance of the catalysts with visible-light illumination.
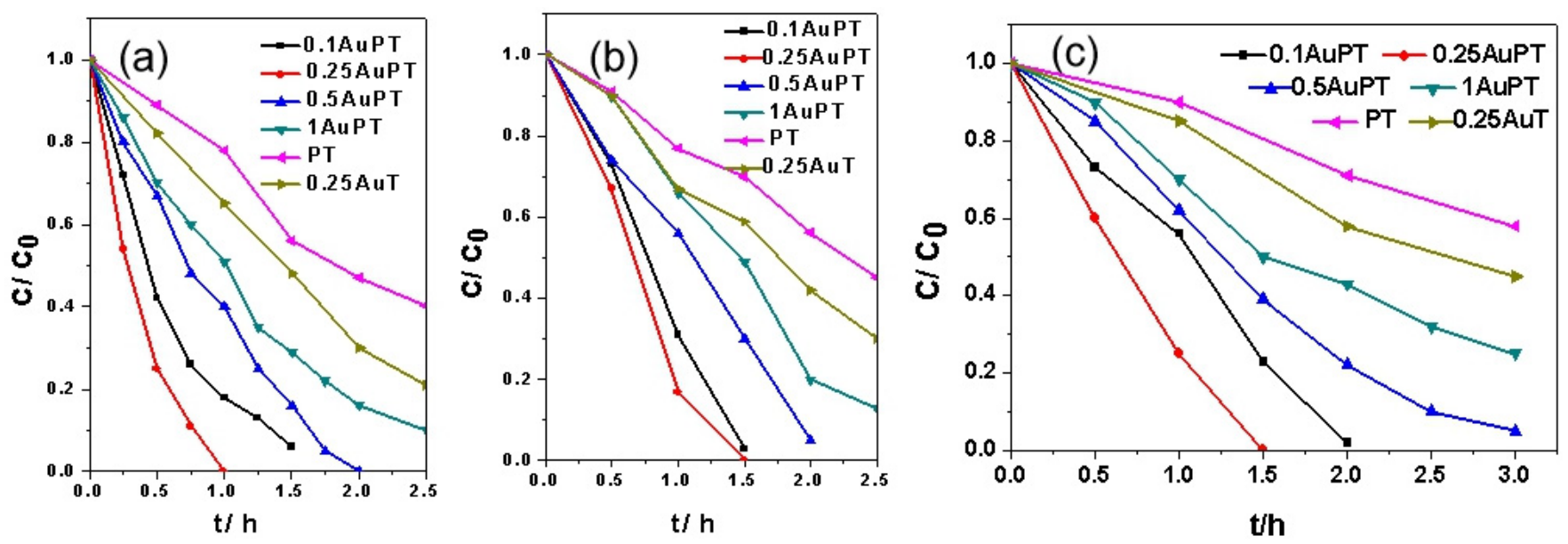

Figure 5. Photocatalytic degradation of (a) $\mathrm{RhB},(\mathbf{b}) \mathrm{MO}$, and (c) phenol on fresh i AuPT, PT, and $\mathrm{Au} / \mathrm{TiO}_{2}(\mathrm{denoted}$ as $0.25 \mathrm{AuT})$ catalysts under visible light $(\lambda \geq 420 \mathrm{~nm})$. Reaction conditions: photocatalyst content: $1 \mathrm{~g} \mathrm{~L}^{-1} ; \mathrm{C}_{0}=5 \mathrm{ppm}$.

We further investigated the photocatalytic performance in terms of visible-light oxidation of thiol and thiophene, which are much more difficult to oxidize, to find out whether a significant improvement still existed. As shown in Figure 6, the complete oxidation of thiol on $0.25 \mathrm{AuPT}$ was achieved in $4 \mathrm{~h}$; however, the conversion of thiol on $\mathrm{TiO}_{2}$ in $6 \mathrm{~h}$ was approximately $67 \%$. Thiophene is more difficult to oxidize, largely due to its aromaticity and low electron density on the $S$ atom [4]. Thiophene was oxidized to a limited degree in $6 \mathrm{~h}$ under visible-light irradiation in our experiments, but the conversion of thiophene on $0.25 \mathrm{AuPT}$ (ca. 55\%) was much higher than that on $\mathrm{TiO}_{2}$ (ca. 12\%). Compared with bare $\mathrm{TiO}_{2}$, we found that the synergistic effect of the Au NPs' SPR effect and the POM molecules was very important for enhancing the photocatalytic activity of $\mathrm{TiO}_{2}$. 


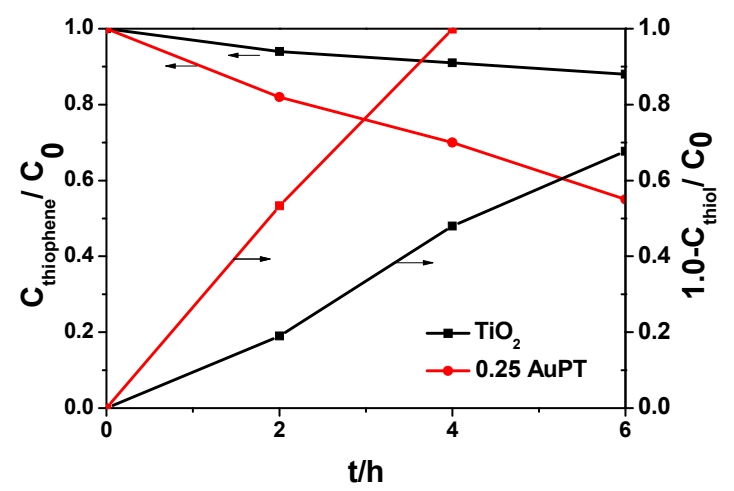

Figure 6. Photocatalytic oxidation of thiophene (left $Y$ axis) and thiol (right $Y$ axis) on the fresh $0.25 \mathrm{AuPT}$ and $\mathrm{TiO}_{2}$ catalysts under visible-light irradiation $(\lambda \geq 420 \mathrm{~nm})$. Reaction conditions: [sulfur concentration $]_{\text {initial }}=600$ ppm; photocatalyst content: $1 \mathrm{~g} \mathrm{~L}^{-1} ; \mathrm{O}_{2}$ (bubbled into the system); reaction time: $6 \mathrm{~h}$.

\subsection{Proposed Reaction Mechanism}

To find the reaction pathway in the simulated actual reaction condition, the ESR spintrap in situ technique was used to probe the active oxygen species such as $\bullet \mathrm{OH}$ or $\mathrm{O}_{2}{ }^{--}$ produced in the photocatalytic reaction. Figure 7 shows the ESR spectra collected from the in situ ESR tests. No ESR signal appeared in the dark, neither without a photocatalyst nor with $\mathrm{POM} / \mathrm{TiO}_{2}$ as a photocatalyst. After illumination for 2 min with the AuPT catalyst, a signal centered at $\mathrm{g}=2.0065$ was obtained [26]. However, there was no signal for either $\mathrm{POM}$ or $\mathrm{TiO}_{2}$ under the light. The characteristic quartet peaks with AuPT were attributed to the DMPO-OH adduct. The hyperfine splittings were $\mathrm{a}_{\mathrm{H}}=\mathrm{a}_{\mathrm{N}}=1.48 \mathrm{mT}$, where $\mathrm{a}_{\mathrm{N}}$ denotes the hyperfine splitting of the nitroxyl nitrogen, and $\mathrm{a}_{\mathrm{H}}$ denotes hyperfine splittings of a-hydrogen [26,27]. We observed a typical 1:2:2:1 lineshape with AuPT, which resulted from the DMPO-OH adduct. The results demonstrate that $\bullet \mathrm{OH}$ was formed only in the presence of the AuPT catalyst under the light. Moreover, the signals' intensity decreased clearly after a $4 \mathrm{~min}$ illumination, because the $\mathrm{h}^{+}$produced during the illumination oxidized the DMPO-OH adduct. As a result, we found that $\bullet \mathrm{OH}$ with a strong oxidation ability was produced clearly in the photocatalytic reaction only with the AuPT catalyst. No active oxygen species appeared with $\mathrm{POM}$ or $\mathrm{TiO}_{2}$ as a catalyst. Of course, for the AuPT catalyst, the simultaneous existence of the Au NPs and POM was beneficial for the efficient separation and transfer of the photoexcited electrons and holes, respectively, and the production of the active oxygen species $\bullet \mathrm{OH}$ was accelerated, which was conducive to the oxidation of pollutants in the reaction system. This synergistic effect of the POM and Au on $\mathrm{TiO}_{2}$ could be an important reason for the good photocatalytic performance of the AuPT.

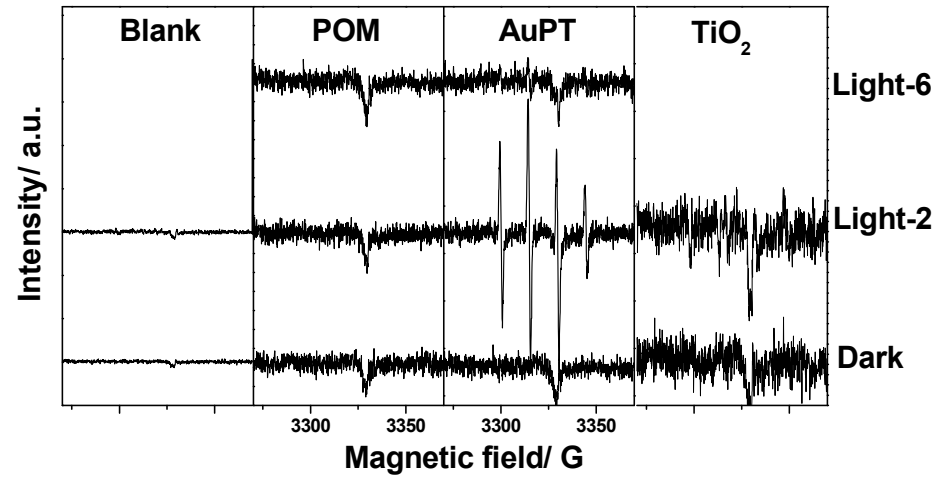

Figure 7. ESR spectra of active oxygen species generated in the in situ photocatalytic reaction with different catalysts. The reaction without photocatalyst: "Blank". The reaction without light irradiation: "Dark". The reaction after irradiating for 2 min: “Light-2"; similarly, 4 min: "Light-4". 
On basis of these outcomes, the mechanism for the photocatalytic oxidation of the contaminants on the AuPT was found to be as follows. The deduced photocatalytic reaction process included the following steps (Scheme 1): (i) under visible-light irradiation through the relaxation of local plasma dipoles on the surface of the semiconductor, the RET course of the Au NPs directly excited the $\mathrm{e}^{-}-\mathrm{h}^{+}$pairs in $\mathrm{TiO}_{2}$ without radiation. The RET course was considered a non-radiative mechanism of the SPR-induced charge separation in the semiconductors. It is proposed that the Au NPs in the AuPT catalysts facilitated the plasma energy transfer in the form of the RET course [18-20]. (ii) The Au NPs on the $\mathrm{TiO}_{2}$ surface with a low Fermi level (0.5 eV versus NHE [28]) may constitute an electron trap that delayed the recombination of the photogenerated electrons and holes in $\mathrm{TiO}_{2}$ and prolonged their lifetime [29]. The photogenerated electrons transferred to the oxidant $\mathrm{O}_{2}$ molecules on the surface of the Au NPs, on which the active oxygen species $\bullet \mathrm{OH}$ were formed if the $\mathrm{O}_{2}$ reacted with the photogenerated electrons $[29,30]$. (iii) $\mathrm{POM}$ entered an oxidative state (POM-ox) via one-electron oxidation on the surface of $\mathrm{TiO}_{2}$. The electrons produced when the POM became reduced (POM-red) could be transferred to the $\mathrm{O}_{2}$ to produce $\bullet \mathrm{OH}$ for the next oxidation reaction of the pollutants. (iv) The photogenerated holes transferred to the $\mathrm{TiO}_{2}$ surface can be concurrently employed as oxidants. $\mathrm{OH}^{-}$reacted with the holes in the reaction to generate $\bullet \mathrm{OH}[4,29,30]$. The reaction of photogenerated holes and $\bullet \mathrm{OH}$ with the contaminants molecules caused strong oxidation reactions. Step (ii) and step (iii) were carried out simultaneously, and the fact that the SPR effect cooperated with the redox transformation of POM was good for the split and transmission of the photoexcited electrons/holes and oxidation of contaminants, resulting in the high photocatalytic activity of the oxidation of the pollutants. This synergistic effect of the POM and $\mathrm{Au}$ on $\mathrm{TiO}_{2}$ accelerated the production of the active oxygen species $\bullet \mathrm{OH}$ and led to the high photocatalytic oxidation activity of the catalysts.

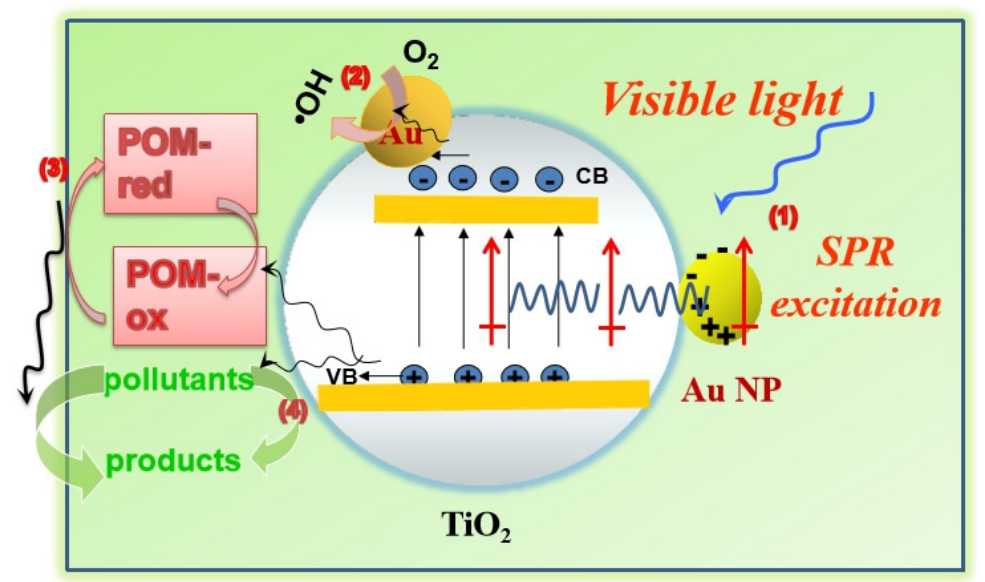

Scheme 1. Schematic illustration of the mechanism for the photocatalytic oxidation of pollutants (such as phenol) on the AuPT photocatalyst.

\section{Materials and Methods}

\subsection{Fabrication of AuPT Catalysts}

There was no further treatment of the chemicals used in the experiments. The POM $\mathrm{Co}_{\text {II }} \mathrm{W}_{11} \mathrm{O}_{39} \mathrm{Sn}_{\text {IV }} \mathrm{OH}_{8}$ was prepared according to the following method. First, we prepared $100 \mathrm{~mL}$ aqueous solution with $18.2 \mathrm{~g} \mathrm{Na}_{2} \mathrm{WO}_{4} \cdot 2 \mathrm{H}_{2} \mathrm{O}$, and then the $\mathrm{pH}$ of the solution was adjusted to 6 by glacial acetic acid. The above solution was heated until boiling. Then, $20 \mathrm{~mL}$ aqueous solution with $1.2 \mathrm{~g} \mathrm{Co}(\mathrm{Ac})_{2} \cdot 4 \mathrm{H}_{2} \mathrm{O}$ and $50 \mathrm{~mL}$ aqueous solution with $3.6 \mathrm{~g} \mathrm{SnCl}_{4} \cdot 5 \mathrm{H}_{2} \mathrm{O}$ were dropped, respectively, into the boiling solution. After the $\mathrm{pH}$ of the mixed solution was adjusted to 2 with $4 \mathrm{M} \mathrm{HCl}$, the temperature of the solution was kept at $80-90^{\circ} \mathrm{C}$ for $1 \mathrm{~h}$. Finally, the blue precipitate POM was obtained, which was filtered, washed, and dried at room temperature for $12 \mathrm{~h}[11,12]$. Then, the $\mathrm{POM} / \mathrm{TiO}_{2}$ catalyst (denoted as PT) was prepared as follows: $80 \mathrm{mg} \mathrm{TiO} 2$ powder was immersed in 
$7.02 \times 10^{-5} \mathrm{M}$ POM solution. The suspension was fiercely stirred for $6 \mathrm{~h}$. Finally, after the mixture was washed, filtered, and dried in a vacuum oven at $50^{\circ} \mathrm{C}$ for $12 \mathrm{~h}$, the PT catalyst was obtained.

The Au NPs were deposited on the PT according to the following method. Excessive $\mathrm{NaBH}_{4}$ was rapidly added $\left(0.3 \mathrm{M}\right.$, aq., $\left.\mathrm{NaBH}_{4} / \mathrm{Au}(\mathrm{mol} / \mathrm{mol})=5\right)$ to an aqueous solution of $\mathrm{HAuCl}_{4}$ with polyvinyl alcohol (PVA) as a protection agent under vigorous stirring. After vigorous stirring for $1 \mathrm{~h}$, PT was added to Au sol in order to obtain an i wt.\% Au-loaded PT catalyst [4].

The products were filtrated and washed thoroughly before drying at $80{ }^{\circ} \mathrm{C}$ in a vacuum oven for $24 \mathrm{~h}$. The as-synthesized catalysts containing i wt.\% Au NPs were denoted as i AuPT.

\subsection{Characterization}

The XRD patterns of the catalysts were obtained by XRD (Rigaku D/Max-2500/PC powder diffractometer, Rigaku Corporation, Tokyo, Japan) using $\mathrm{Cu}-\mathrm{K}_{\alpha}$ radiation (40 kV and $200 \mathrm{~mA}$ ). The scan area of $2 \mathrm{q}$ was $8-80^{\circ}$, and the scan rate was $5^{\circ} / \mathrm{min}$ with a step of $0.02^{\circ}$.

UV-visible diffuse reflectance spectra were collected on a UV-vis spectrophotometer (Jasco V-550) with an added integrating sphere. The morphologies, compositional distribution, and particle sizes of the catalysts were detected by a Quanta 200 FEG scanning electron microscope (Hitachi Corporation, Tokyo, Japan) and a JEM-2100F high-resolution transmission electron microscopy (HR-TEM, JEOL Corporation, Tokyo, Japan), which is operated at an accelerating voltage of $200 \mathrm{kV}$.

XPS was obtained using Thermo ESCALAB 250Xi equipped with an Al Ka X-ray (the h $v$ was $1486.6 \mathrm{eV}$ ). The base pressure in the analysis chamber stayed at $10^{-8} \mathrm{~Pa}$. The spectrometer featured an energy resolution of $0.8 \mathrm{eV}$ (the passing energy was $20 \mathrm{eV}$ ). Full width at half maximum (FWHM) was calibrated at $0.65 \mathrm{eV}$ relative to $\mathrm{Ag} 3 \mathrm{~d}_{5 / 2}$ FWHM. The error in all the BE values reported was $0.4 \mathrm{eV}$.

Infrared spectra (IR) with a resolution of $4 \mathrm{~cm}^{-1}$ and 32 scans were acquired on a Fourier transform infrared spectrometer (Nicolet NEXUS 470, Nicolet Corporation, Wisconsin, USA). For the typical experimental procedure, before being moving into the sample holder of the infrared cell, a $20 \mathrm{mg}$ sample was first pressed into a self-supporting thin wafer (15 mm diameter). The background and sample spectra of the samples were recorded.

An ESR spectrometer (Brucker A200, Brucker Corporation, Karlsruhe, Germany) was used to record the ESR signals for the radicals trapped by DMPO. The materials were introduced into a quartz cup in a microwave cavity, and a CERAMAX LX-300 Xe lamp was employed for illumination. The major setting parameters were center field, $3320 \mathrm{G}$; scanning width, $100 \mathrm{G}$; microwave frequency, $9.32 \mathrm{GHz}$; modulation frequency, $100 \mathrm{kHz}$; and power, $9.95 \mathrm{~mW}$.

\subsection{Photocatalytic Reactions}

The photocatalytic degradation was performed in a Pyrex reaction cell. For the dye contaminants such as rhodamine B (RhB), methyl orange (MO), and phenol, $50 \mathrm{mg}$ of catalyst was added into $50 \mathrm{~mL}$ of aqueous solution containing $5 \mathrm{ppm}$ of dye. The suspension was stirred in the dark for $30 \mathrm{~min}$ to establish the adsorption/desorption equilibrium between the dye and the catalyst and then irradiated with a $300 \mathrm{~W}$ Xe lamp (Ceramx LX-300, Perfectlight Corporation, Beijing, China). The temperature was controlled at $10-12{ }^{\circ} \mathrm{C}$ by flowing cooling water. We used a UV-vis spectrometer for colorimetric measurement to monitor the concentration of dyes. The $\lambda_{\max }$ for $\mathrm{RB}, \mathrm{MO}$, and phenol were $553,467 \mathrm{~nm}$, and $270 \mathrm{~nm}$, respectively. The content of the dye contaminants was quantified employing calibration according to the Beer-Lambert law.

Similarly, for the sulfur contaminants such as thiophene and methanethiol, $50 \mathrm{mg}$ catalyst was added to $50 \mathrm{~mL}$ acetonitrile solution containing $600 \mathrm{ppm}$ sulfur. The suspension was also stirred in the dark for $30 \mathrm{~min}$ and then irradiated under a 300W Xe lamp equipped 
with an optical filter $(\lambda \geq 420 \mathrm{~nm})$ to cut off the ultraviolet light. The temperature was controlled at $5-7^{\circ} \mathrm{C}$ by flowing cooling water. After the reaction, the catalyst was filtered out, and the products were analyzed by GC-FPD (Agilent 7890, FFAP column, Agilent Corporation, Santa Clara, CA, USA).

\section{Conclusions}

The SPR-mediated visible-light-responsive photocatalyst AuPT achieved high conversion of the contaminants' (phenol, $\mathrm{RhB}, \mathrm{MO}$, thiol, and thiophene) oxidation reaction under visible-light irradiation. This new type of POM and Au NPs were simultaneously assembled onto the semiconductor. The experimental results suggest that the Au SPR effect markedly enhances the electron-hole pair separation ability of $\mathrm{TiO}_{2}$. The synergistic effect of the resonant energy transfer (RET) course and redox transformation of POM can be advantageous to the efficient transmission of photoexcited electrons and holes in a way that achieves efficient photocatalytic oxidation of contaminants.

Supplementary Materials: The following are available online at https:/ /www.mdpi.com/article/ 10.3390/catal11091045/s1. Figure S1: Photocatalytic degradation of RhB on catalysts for one hour with illumination of monochromatic light of $380 \mathrm{~nm}, 420 \mathrm{~nm}$, and $540 \mathrm{~nm}$ (optical filter). Figure S2: The element composition of AuPT catalyst. Table S1: The element composition and proportion of AuPT catalyst.

Author Contributions: Conceptualization, F.L. and G.Z.; methodology, Z.Z. and Y.Y.; validation, Y.Y. and F.L.; formal analysis, Z.Z. and N.T.; investigation, N.T. and F.L.; resources, F.L.; data curation, F.L. and G.Z.; writing —original draft preparation, F.L. and Y.Y.; writing—review and editing, G.Z. and N.T.; supervision, G.Z.; project administration, F.L.; funding acquisition, F.L. All authors have read and agreed to the published version of the manuscript.

Funding: This research received no external funding.

Acknowledgments: This research was supported by the National Natural Science Foundation of China (Grant No. 21802134) and the Liaoning Revitalization Talents Program (Grant No. XLYC2007136).

Conflicts of Interest: The authors declare no conflict of interest.

\section{References}

1. Tian, J.; Zhao, Z.; Kumar, A.; Boughton, R.; Liu, H. Recent progress in design, synthesis, and applications of one-dimensional $\mathrm{TiO}_{2}$ nanostructured surface heterostructures: A review. Chem. Sci. Rev. 2014, 43, 6920-6937. [CrossRef]

2. Li, W.; Elzatahry, A.; Aldhayan, D.; Zhao, D. Core-shell structured titanium dioxide nanomaterials for solar energy utilization. Chem. Sci. Rev. 2018, 47, 8203-8237. [CrossRef]

3. Tseng, E.; Hsiao, Y.; Chen, Y.; Chen, S.; Gloter, A.; Song, J. Magnetism and plasmonic performance of mesoscopic hollow ceria spheres decorated with silver nanoparticles. Nanoscale 2019, 11, 3574-3582. [CrossRef] [PubMed]

4. Lin, F.; Shao, B.; Li, Z.; Zhang, J.; Wang, H.; Zhang, S.; Haruta, M.; Huang, J. Visible light photocatalysis over solid acid: Enhanced by gold plasmonic effect. Appl. Catal. B Environ. 2017, 218, 480-487. [CrossRef]

5. Umakoshi, T.; Saitoa, Y.; Verma, P. Highly efficient plasmonic tip design for plasmon nanofocusing in near-field optical microscopy. Nanoscale 2016, 8, 5634-5640. [CrossRef] [PubMed]

6. Pei, G.X.; Dzade, N.Y.; Zhang, Y.; Hofmann, J.P.; Leeuw, N.H.; Weckhuysen, B.M. Identification of Photoexcited Electron Relaxation in a Cobalt Phosphide Modified Carbon Nitride Photocatalyst. ChemPhotoChem 2021. [CrossRef]

7. Thomann, I.; Pinaud, B.A.; Chen, Z.; Clemens, B.M.; Jaramillo, T.F.; Brongersma, M.L. Plasmon Enhanced Solar-to-Fuel Energy Conversion. Nano Lett. 2011, 11, 3440-3446. [CrossRef] [PubMed]

8. Sadakane, M.; Steckhan, E. Electrochemical Properties of Polyoxometalates as Electrocatalysts. Chem. Rev. 1998, 98, $219-238$. [CrossRef]

9. Maradur, S.P.; Halligudi, S.B.; Gokavi, G. Oxidation of Aliphatic and Benzylic Alcohols by Oxone ${ }^{\circledR}$, Catalysed by $12-$ Tungstocobaltate (II). Catal. Lett. 2004, 96, 3-4. [CrossRef]

10. Wu, Q.; Sang, X.; Shao, F.; Pang, W. Synthesis and conductivity of undecatungstocobaltoindic heteropoly acid. Mater. Chem. Phys. 2004, 92, 16-20. [CrossRef]

11. Yang, Y.; He, J.; Wang, X.; Li, B.; Liu, J. Preparation, characterization and in vitro antitumoral activity of a nanosize liposome complex encapsulated polyoxotungstate $\mathrm{K}_{6} \mathrm{H}_{2}\left[\mathrm{CoW}_{11} \mathrm{TiO}_{40}\right]$. Transit. Met. Chem. 2004, 29, 96-99. [CrossRef]

12. Ji, Y.; Shen, L.; Wang, A.; Wu, M.; Tang, Y.; Chen, Y.; Lu, T. Electrocatalytic performance of carbon supported Pd catalyst modified with Keggin type of Sn-substituted polyoxometalatate for formic acid oxidization. J. Power Sources 2014, 260, 82-88. [CrossRef] 
13. Liu, X.; Iocozzia, J.; Wang, Y.; Cui, X.; Chen, Y.; Zhao, S.; Li, Z.; Lin, Z. Noble metal-metal oxide nanohybrids with tailored nanostructures for efficient solar energy conversion, photocatalysis and environmental remediation. Energy Environ. Sci. 2017, 10, 402-434. [CrossRef]

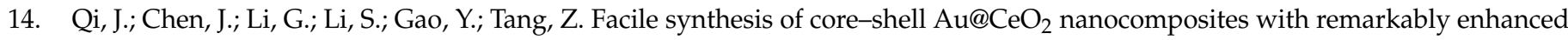
catalytic activity for CO oxidation. Energy Environ. Sci. 2012, 5, 8937-8941. [CrossRef]

15. Bawaked, S.; Dummer, N.; Dimitratos, N.; Bethell, D.; He, Q.; Kielyb, C.; Hutchings, G. Solvent-free selective epoxidation of cyclooctene using supported gold catalysts. Green Chem. 2009, 11, 1037-1044. [CrossRef]

16. Sharma, R.K.; Sharma, S.; Dutta, S.; Zboril, R.; Gawande, M. Silica-nanosphere-based organic-inorganic hybrid nanomaterials: Synthesis, functionalization and applications in catalysis. Green Chem. 2015, 17, 3207-3230. [CrossRef]

17. Eustis, S.; El-Sayed, M.A. Why gold nanoparticles are more precious than pretty gold: Noble metal surface plasmon resonance and its enhancement of the radiative and nonradiative properties of nanocrystals of different shapes. Chem. Soc. Rev. 2006, 35, 209-217. [CrossRef]

18. Cushing, S.K.; Li, J.T.; Meng, F.K.; Senty, T.R.; Suri, S.; Zhi, M.J.; Li, M.; Bristow, A.D.; Wu, N.Q. Photocatalytic Activity Enhanced by Plasmonic Resonant Energy Transfer from Metal to Semiconductor. J. Am. Chem. Soc. 2012, 134, 15033-15041. [CrossRef]

19. Ide, Y.; Matsuoka, M.; Ogawa, M. Efficient Visible-Light-Induced Photocatalytic Activity on Gold-Nanoparticle-Supported Layered Titanate. J. Am. Chem. Soc. 2010, 132, 16762-16764. [CrossRef]

20. Zhang, Q.; Lima, D.Q.; Lee, I.; Zaera, F.; Chi, M.; Yin, Y. A Highly Active Titanium Dioxide Based Visible-Light Photocatalyst with Nonmetal Doping and Plasmonic Metal Decoration. Angew. Chim. 2011, 123, 7226-7230. [CrossRef]

21. Song, J.; Luo, Z.; Zhu, H.; Huang, Z.; Lian, T.; Kaledin, A.L.; Musaev, D.G.; Lense, S.; Hardcastle, K.I.; Hill, C.L. Synthesis, structure, and characterization of two polyoxometalate-photosensitizer hybrid materials. Inorg. Chim. Acta 2010, 363, 4381-4386. [CrossRef]

22. Niu, J.; Wang, Z.; Wang, J. Hydrothermal synthesis and structure characterization of a Keggin tungstocobaltate [Co(2,2'bipy $\left.)_{3}\right]_{2} \mathrm{H}_{2}\left[\mathrm{CoW}_{12} \mathrm{O}_{40}\right] \cdot 9.5 \mathrm{H}_{2} \mathrm{O}$. Polyhedron 2004, 23, 773-777. [CrossRef]

23. Nomiya, K.; Murasaki, H.; Miwa, M. Catalysis by heteropolyacids-VIII. Immobilization of keggin-type heteropolyacids on poly(4-vinylpyridine). Polyhedron 1986, 5, 1031-1033. [CrossRef]

24. Guo, Z.; Han, D.; Wexler, D.; Zeng, R.; Liu, H. Polyoxometallate-stabilized platinum catalysts on multi-walled carbon nanotubes for fuel cell applications. Electrochim. Acta 2008, 53, 6410-6416. [CrossRef]

25. Pan, D.; Tao, W.; Nie, L.; Yao, S. Polyoxometalate-Modified Carbon Nanotubes: New Catalyst Support for Methanol Electrooxidation. Langmuir 2006, 22, 5872-5876. [CrossRef] [PubMed]

26. Harbour, J.R.; Hair, M.L. Detection of superoxide ions in nonaqueous media. Generation by photolysis of pigment dispersions. J. Phys. Chem. 1978, 82, 1397-1399. [CrossRef]

27. Huang, Y.; Li, J.; Ma, W.; Cheng, M.; Zhao, J.; Yu, J.C. Efficient $\mathrm{H}_{2} \mathrm{O}_{2}$ Oxidation of Organic Pollutants Catalyzed by Supported Iron Sulfophenylporphyrin under Visible Light Irradiation. J. Phys. Chem. B 2004, 108, 7263-7270. [CrossRef]

28. Subramanian, V.; Wolf, E.E.; Kamat, P.V. Catalysis with $\mathrm{TiO}_{2} /$ Gold Nanocomposites. Effect of Metal Particle Size on the Fermi Level Equilibration. J. Am. Chem. Soc. 2004, 126, 4943-4950. [CrossRef] [PubMed]

29. Lin, F.; Jiang, Z.; Tang, N.; Zhang, C.; Chen, Z.; Liu, T.; Dong, B. Photocatalytic oxidation of thiophene on $\mathrm{RuO}_{2} / \mathrm{SO}_{4}{ }^{2-}-\mathrm{TiO}_{2}$ : Insights for cocatalyst and solid-acid. Appl. Catal. B Environ. 2016, 188, 253-258. [CrossRef]

30. Sandulescu, A.; Anastasescu, C.; Papa, F.; Raciulete, M.; Vasile, A.; Spataru, T.; Scarisoreanu, M.; Fleaca, C.; Mihailescu, C.N.; Teodorescu, V.S.; et al. Advancements on Basic Working Principles of Photo-Driven Oxidative Degradation of Organic Substrates over Pristine and Noble Metal-Modified $\mathrm{TiO}_{2}$. Model Case of Phenol Photo Oxidation. Catalysts 2021, 11, 487. [CrossRef] 